\title{
The new European Union Strategic Framework for Roma Integration 2020-2030: Insights and recommendations for the national strategic frameworks
}

\author{
Andrei Ghimisi ${ }^{1}$ \\ ${ }^{1}$ National University of Political Studies and Public Administration, \\ E-mail: ghimisi4567@gmail.com
}

\begin{abstract}
The paper "The new European Union Strategic Framework for Roma Integration 2020-2030: Insights and recommendations for the national strategic frameworks" seeks to present some of the most important elements that target specifically the Roma community in the new EU strategic framework. Moreover, after some crucial aspects of the strategy are presented, some key recommendations are presented for the upcoming national strategic frameworks..

Keywords: integration, roma, discrimination
\end{abstract}

\section{Introduction}

The European Commission published a Communication ${ }^{1}$ to the Council and the European Parliament regarding the new Strategic Framework for Roma Equality, Inclusion and Participation for 2020-2030. This framework is therefore replacing the previous EU framework for national Roma integration strategies 2011-2020. The new framework is a positive sign and a great step in the right direction and it changes the perspective of the previous EU framework to a more balanced approach between human rights, social inclusion and empowerment objectives.

Through this new European Union framework, Member States and Enlargement countries are asked to develop national strategic frameworks (NSFs), not just strategies, proposing an intersectional approach to tackle discrimination and defining intersectional discrimination as such for the first time. Antigypsism is also included in the new framework by using the spelling proposed by the Alliance against Antigypsyism. In addition, the framework seeks to address Enlargement countries on an equal footing and acknowledges the importance of the Western Balkan region for the EU, while the Neighbourhood countries are mentioned for the first time in relation to Roma inclusion under the current framework.

The European Council asks States in the guidelines ${ }^{2}$ to recognise antigypsyism and act against it, calling them to dismantle and prevent systemic/institutional/structural discrimination experienced by Roma and prioritises environmental justice. Another important factor that was introduced was the fight against Roma poverty as a specific objective with associated indicators. Even though the guidelines are in general very good, they leave it up to governments to pick and choose what to include in their own frameworks.

Other several relevant initiatives that the EU Roma strategic framework contributed to were namely to implementing the EU anti-racism action plan, the European Pillar of Social Rights and to the

\footnotetext{
${ }^{1}$ Commission Communication available at : https://ec.europa.eu/info/publications/ new-eu-roma-strategicframework-equality-inclusion-and-participation-full-package_en

${ }^{2}$ Ibid.
} 
achievement of the UN Agenda 2030 and Sustainable Development Goals. In addition, there is no mention that the Social Pillar and SDGs will also contribute to implementing the Roma framework in mutually reinforcing processes. Another aspect that was neglected was the interplay of the Framework with the European Semester and the European Green Deal, and how Roma inclusion, equality and participation will be mainstreamed in these overarching EU policy processes.

\section{Horizontal Priorities in the new European Union Roma strategic framework}

\subsection{Fight against discrimination}

One of the most important and urgent needs is that the efforts to tackle discrimination and to promote equality and inclusion of Roma people, this needs that have been stressed out more by the pandemic context. According to The Fundamental Rights Agency, $41 \%$ of Roma people reported that they had felt discriminated at the work place or while they were searching for a work place, in education, in healthcare, when they were in contact with state authorities or when they entered a store ${ }^{3}$.

\subsection{Reducing exclusion and poverty}

With over more than $80 \%$ of Roma at risk of social exclusion and poverty ${ }^{4}$, prioritising poverty reduction as a cross-cutting objective, accompanied by concrete targets and associated indicators is a welcome improvement from the previous Roma framework. One target that is well received is the one that refers to reducing the poverty gap and child poverty gap by at least half, but recommend national governments to go even further the minimum target and adjust the strategy to their own poverty rates

\subsection{Promoting participation through cooperation, trust and empowerment}

The importance on Roma participation in the EU framework and the vital role that Roma and pro-Roma civil society should play in designing, implementing, monitoring, and evaluating policies that seek to promote the equality and inclusion of Roma is appreciated in the new EU framework. These measures should be accompanied with strong participation targets at the member state level, and genuine participation of Roma civil society in the implementation, development, monitoring and evaluation of National Roma Strategic Frameworks

\section{Sectorial priorities in the new European Union Roma strategic framework: Education, Housing, Employment and Health}

\subsection{Education}

With regards to education, the framework needs to be more ambitious as education stand at the root of many inequalities that strove from this early moments. For example, the proposed target of reducing the gap in upper-secondary school completion by only $1 / 3$ is not sufficient. In addition, allowing the continuing practice of segregation of Roma children in schools, decreasing by only a half the proportion of Roma children attending segregated primary schools goes against EU law, as segregation is considered racial discrimination according to the Committee on the Elimination of Racial Discrimination. $^{5}$

\footnotetext{
${ }^{3}$ FRA (2016). Op. cit. note 3.

${ }^{4}$ Communication from the Commission to the European Parliament and the Council, October 2020. A Union of Equality: EU Roma strategic framework for equality, inclusion and participation 2020-2030. https://ec.europa.eu/info/sites/info/files/eu_roma_strategic_framework_for_equality_inclusion_and_p articipation_for_2020_-_2030_0.pdf

${ }^{5}$ ERGO, December 2020 . Op. cit. note 12
} 


\subsection{Housing}

Some of the targets that relate to housing, including cutting the gap in overcrowding between the Roma and the general population by at least $1 / 2$ (it currently is $78 \%$ versus $17.1 \%$ for the general population), ensuring that at least $95 \%$ of Roma have access to tap water and reducing by at least $1 / 3$ the gap in housing depravation 3 are all good targets and a positive step in seeking to address some of the persistent challenges that Roma face with regards to housing. However, forced evictions and housing segregation remain major challenges for Roma people. Strong measures addressing forced evictions and housing segregation should therefore be included in National Roma strategic Frameworks

\subsection{Employment}

About this area, there are serious steps that need to be made in order to reduce many of the gaps that had spread even more in time. With $62 \%$ of Roma youth neither in education, employment nor training, a gender employment gap of 27 percentage points (pps), compared to 11.7 pps gap in the general population and only $43 \%$ of Roma aged 20-64 in paid work making effective equal access to quality and sustainable employment as a sectoral priority in the EU Framework is not only well welcomed but also necessary.

\subsection{Health}

The measures that were developed in regards to the healthcare system and its access for the Roma people are very well shaped and addresses many of the problems of the community. As many vulnerable groups among Roma are not covered by health insurance, they frequently face difficulties accessing basic health care, and often can only access emergency health care services. The target to decrease the gap in life expectancy between Roma and non-Roma by at least a half - which currently is very high at 10 years, is a big step forward in properly addressing this issue. In addition, for those vulnerable groups of Roma people living in isolated rural areas or camps in the outskirts of cities with limited public transport facilities, accessing health care centres or professionals is often a challenge ${ }^{6}$

\section{Further recommendations for the future national strategic frameworks}

Even though the new European Union Roma strategic framework addressed many problems and managed to make vital changes in some crucial areas, there is a short period of time until September 2021 when Member States need to present their national strategic frameworks. Therefore, there are still some areas in which improvement can be made and also some key recommendations regarding the wellbeing of Roma people.

National strategic frameworks need to ensure that national and European Union funds are used towards inclusive mainstream policy reform, communication and targeted action for Roma inclusion, equality and participation at local and national levels.

In addition, the national strategic framework of each Member State needs to ensure civil society and an institutional consolation and coordination mechanism that is built in a transparent way and the provision of access to information is guaranteed. Also, they need to ensure effective and full participation of Roma and pro- Roma civil society at all levels and all stages of the national strategic frameworks implementation, design, monitoring and evaluation.

Another key recommendation is that national strategic frameworks need to ensure an appropriate and adequate response, at national levels, to the particular risks experienced by Roma communities due to the Covid-19 pandemic and ensure an appropriate and adequate mainstreaming and inclusion of Roma communities in the social and economic policies and programmes deployed to address and restore the impact of pandemic.

Roma women and youth must be at the centre of all policies and processes affecting them, while gender mainstreaming needs to be effectively implemented and monitored throughout thematic areas.

\footnotetext{
${ }^{6}$ Eurodiaconia, Promoting Roma Inclusion, Policy Paper, February 2018
} 
Enhance the role and mandate of National Roma Contact Points (NRCPs) under the NSFs. Additionally, involve NRCPs in the elaboration of mainstream inclusion policies, especially those under the national recovery plans, green and digital inclusion to ensure congruence and mutual reciprocity with NSFs.

Address difficulties for Roma in securing adequate personal documentation and use of civil registration systems and secure an effective response to the difficulties for Roma in moving to another Member State or enlargement country.

Include Roma, in full alignment with the objectives and targets of the EU Strategic Framework, in the preparation of National Recovery and Resilience Plans by April 2021, especially in support of job creation and economic and social resilience, contribute to environmental sustainability and foster digital transformation.

One sector that needs more attention and that is also put by the European Union at the centre of its strategy is the fight against poverty, racism, discrimination and segregation. Therefore, there are some key recommendations in this sector that will help the national strategic frameworks to implement them easier and faster.

Member States and Enlargement Countries should put in place measures to ensure adequacy of real needs, as well as better coverage and take-up of social benefits, such as adequate minimum income schemes, by making them automatic, reducing red tape, eliminating conditionality's and sanctions, and tackling stigma and discrimination against Roma or other recipients.

The target of poverty cut in half should start from the actual poverty numbers throughout the country. This means if the country has now $40 \%$ poverty of Roma, it should be down to $20 \%$, while ensuring that there are no pockets of poverty at regional level that still reach $80 \%$ in some regions. There should also be a minimum target of $40 \%$ in every region at national level.

Roma poverty should be measured annually through Eurostat, using the combined AROPE indicator - at risk of poverty, material deprivation and households with low work intensity - to be able to keep track of the multifaceted aspects of poverty and social exclusion in Roma communities.

One action that needs to be addressed is that Member States and Enlargement countries should fully implement, by 2030, UN Sustainable Development Goal 1 on No Poverty, as well as the entirety of the European Pillar of Social Rights and the full set of indicators of the Social Scoreboard, as $80 \%$ of the Roma in Europe are currently experiencing poverty and social exclusion.

Member States and Enlargement Countries should provide anti-discrimination training to public offices disbursing social protection and penalise discriminatory behaviours in relation to minority recipients, including the Roma. It is necessary to combat the public discourse that stigmatises benefit claimants and people experiencing poverty.

National strategic frameworks should include minimum standards or measures on the implementation of the right to participation to ensure effective and full participation of Roma at all levels and all stages of the national strategic frameworks implementation, design, monitoring and evaluation, by suggesting a minimum benchmark of $50 \%$ based on self-identification, with a provision on gender equality. This involves making adequate human and financial resources available to allow for proper participation processes, and providing public servants with training on, and sufficient time for, engaging such organisations. Tools and methods used by public authorities for implementing participation could be diversified and improved.

Another important area in which national strategic frameworks need to thrive is education. Therefore, Member States and Enlargement countries should go much above the targets set by the European Commission in the area of preschool, primary and secondary education. States should ensure full implementation of the SDGs for Roma children, youth, men and women by 2030, ensure equitable access to quality mainstream education for all Roma children and increase the enrolment and completion rate of Roma in quality integrated primary education to $90 \%$, and in secondary education to $50 \%$.

By 2030, Member States need to ensure that all Roma girls and boys complete free, equitable and quality primary and secondary education leading to relevant and effective learning outcomes 
By 2030, national strategic frameworks need to ensure that all Roma girls and boys have access to quality early childhood development, care and pre-primary education so that they are ready for primary education.

An important recommendation in regards to the employment of the Roma people is that national strategic frameworks need to aim to increase the Roma employment rate equally for men and women in the public sector to $75 \%$, equivalent to the proportion of Roma in the overall population (the current target is at $60 \%$ for men only). $75 \%$ of the Roma population aged 20 to 64 should be in quality and sustainable work, also by overcoming the gender gap in the labour force.

\section{Conclusion}

In conclusion, the new European Union Strategic Framework for Roma Integration 2020-2030 is a big step towards resolving a problem that has been stretched out for far too long. The Roma population, which is the most numerous minority in the European Union, has suffered too much at the hands of discrimination, inappropriate medical care or lack of a proper education. Through many efforts, the European Union seeks to address many of these problems with its new strategic framework, designed especially for the proper integration of Roma people.

Now, after this signal from the European Union, all Member States need to react and comprehend the moment, seize it and make the full out of every target. They will also need to take care in addressing some of the problems, as the Roma community is sensible and needs to trust the changes. An important factor that is well shaped this time is the role of the NGO's and other important actors who now have a new strategic framework to study and create a proper method in which the measures will be implemented on their respective territory

\section{References}

[1] Commission Communication available at : https://ec.europa.eu/info/publications/ new-eu-romastrategic-framework-equality-inclusion-and-participation-full-package_en

[2] FRA (2016)

[3]. Communication from the Commission to the European Parliament and the Council, October 2020. A Union of Equality: EU Roma strategic framework for equality, inclusion and participation 2020-2030.

https://ec.europa.eu/info/sites/info/files/eu_roma_strategic_framework_for_equality_inclusio n_and_p articipation_for_2020_-_2030_0.pdf

[4] ERGO, December 2020

[5] Eurodiaconia, Promoting Roma Inclusion, Policy Paper, February 2018

"This paper was elaborated within the Human Capital Operational Program 2014-2020, co-financed by the European Social Fund, under the project POCU/380/6/13/124708 no. 37141/23.05.2019, with the title "Researcher-Entrepreneur on Labour Market in the Fields of Intelligent Specialization (CERT-ANTREP)", coordinated by the National University of Political Studies and Public Administration. 